Zhao, H., \& Chen, L. (2016). How Can Self-regulated Learning Be Supported in E-learning 2.0 Environment: a Comparative Study. Journal of Educational Technology Development and Exchange, 9(2), 1-20.

\title{
How Can Self-regulated Learning Be Supported in E-learning 2.0 Environment: a Comparative Study
}

\author{
Hong Zhao \\ Beijing Normal University \\ Li Chen \\ Beijing Normal University
}

\begin{abstract}
As a critical factor that affects the learning performance in distance education, selfregulated learning (SRL) has elicited considerable interest. Self-regulated learners can manage their learning activities efficiently but researchers indicate that learners have difficulties in SRL behavior. Thus, providing support to facilitate self-regulatory processes is important. E-learning has the potential to be a learning tool to examine students'self-regulatory skills. New advances in technology, especially the development of Web 2.0 technology, have provided effective support for self-regulated learning. This study addresses the following research question: How can SRL be supported properly in E-learning environment? Because learning processes cannot be conceptualized without the sociocultural context this study investigate environmental variations between two samples of Mainland China and Hong Kong distance learners $(N=289)$. The purpose is to chart the underlying relationships between learner self-regulation and distance education environments using regression analysis and to find differences of environmental factors and self-regulation in different cultural orientations. The study has found significant differences between Mainland China and Hong Kong distance students on demography variables except age characteristics. In the relation model however, no difference has been found. Self-regulation is to be equivalent in the two cultures and can be influenced by the same environmental factors.
\end{abstract}

Keywords: self-regulated learning, distance environment

\section{Introduction}

There is increasingly empirical evidence showing that self-regulated ability is an effective key factor in predicting students' academic achievements in e-learning environment (Zimmerman \& Schunk,
2001; Liaw \& Huang, 2013). In e-learning environment, students are responsible for their own studies and have to actively take part in the management of learning process. They have to set learning objectives, monitor and introspect their own learning processes, and evaluate learning outcomes. However, 
researchers have found that these selfregulated learning processes are not taking place naturally for most of learners. In general, learners could not realize that they should manage their own learning processes and do not know how to effectively regulate these processes. Therefore, supports are needed to help learners acquire effective self-regulating strategies(Kramarski \&Mevarech 2003; Azevedo et al., 2004). For students, how to learn and what to learn were largely determined by the learning environment provided by distance education institutions(AI-Harthi, 2010).In other words, self-regulated learning process is organized and guided by the learning environment (Kitayama, 2002).Therefore, what kind of online learning environment can effectively promote self-regulated learning? What components should be included in an effective online self-regulated learning environment? Based on the questions above, the composition of a successful online self-regulated learning environment was discussed in the present research and a survey of online learning environments was designed accordingly. That is to say what factors have impact on students' self-regulated learning. Furthermore, a survey of online learning environments and a comparative study have been conducted based on the above questions.

\subsection{E-learning 2.0Environment Plays a Role in Promoting Self-regulated Learning}

E-learning, as a new mode of modern distance education, provides a dynamic, interactive and nonlinear learning environment for learners through a series of synchronous or asynchronous network communication technologies. It breaks the limit of time and space and offers an opportunity for students' self-regulated learning. In recent years, Web2.0 technology represented by social software such as blogs, Facebook, Twitter and wiki had been widely used in e-learning, which enabled learners to achieve more participation and collaboration in dynamic social interaction of creating, communicating, and sharing knowledge.

Though there is no consistent definition of Web2.0, the core characteristics of "interaction, participation and sharing" give the medium a great potential for effectively supporting learners' self-regulated learning. This potential has been tested by many researchers. Kitsantas and Dabbagh (2010) thought that e-learning 2.0 environment had the teaching function of helping and promoting students' self-regulated learning. They took three kinds of social software to analyze how teachers made use of social software to promote students' self-regulated learning. Furthermore, they pointed out that Web2.0 social software achieved innovation in supporting students' self-regulated learning. Harrison (2011) surveyed the application status of blogs used by undergraduates for the study. He found that blogs contributed to the management of one's own studies, as well as the increase of students' participation and promoted the development of informal learning community. Hilton (2009) emphasized that Web2.0 tools, especially the social software, supported students for managing their own studies. Chen (2009) believed that Web2.0 technology provided strongly self-regulated tools for students, and thus, made self-regulated learning available for students and helped improved students' academic. Liaw and Huang (2013) proved that learning motivation can be stimulated by establishing an effective interactive online learning environment, thus promoting students' self-regulated learning. From the research, e-learning 2.0 environment had an advantage in supporting and promoting students' self-regulated learning. Therefore, designing and developing effective online 
learning environment to promote learners' self-regulated learning has been the primary task for both of practitioners and researchers of distance education.

\subsection{Factors for the Success of e-Learning Environment}

The issue of what factors and characteristics should be included in a successful e-learning 2.0 environment has been discussed by many researchers. Previous studies suggested that users' satisfaction was one of the key factors in evaluating whether a learning environment was successful or not. For example, Liaw and Huang (2007) thought that four factors (environmental usefulness, learners' satisfaction to environment, the effectiveness of learning activity and learners' characteristics) should be considered when developing an e-learning environment. Furthermore, Liaw and Huang (2013 thought that users' satisfaction referred to the combination of users' feeling and experience, especially expressed as the acceptance degree to learning environment. Additionally, learners' satisfaction with the learning environment determined whether or not learners wanted to study in that environment. A lot of research proved that users' satisfaction was highly correlated to self-regulated learning, a crucial factor that had affected learners' self-regulated learning in an e-learning environment (Kramarski \& Gutman, 2006; Liaw \& Huang, 2013; Roca \& Gagne, 2008). Therefore, how to improve users' satisfaction in an e-learning environment has become a hot issue discussed by many researchers.

At the same time, a number of correlational research and success models of information system have emerged. The D\&M model was one of the most widely referenced and tested models by these researchers. In 1992, DeLone and McLean first proposed a success model of information system consisting of six factors that they had adjusted and upgraded in 2003. This model proposed a theoretical framework for evaluating information systems. According to D\&M model, six factors determined whether or not a learning system was successful: information quality, system quality, service quality, adoption intention, users 'satisfaction, and net benefit. Many researchers proposed a new model based on D\&M. For example, Wang, Wang, and Shee (2007) proposed a success model of e-commerce consisting of five factors: system quality, service quality, information quality, users' satisfaction, and the intention to use it again. Seddon (1997) who proposed a new model based on the analysis of D\&M (1992) thought determining whether or not an environment was successful could be based on five factors including system quality, information quality, perceived usefulness, individual income, and organization income. Wang and Chiu (2011) proposed a new success model of learning system aimed at the e-learning 2.0 environment. This model reformed the D\&M model by adopting the "quality-satisfaction-loyalty" theoretical model, and communication quality had been added to the new model, while net benefit was replaced with loyalty intention. In the $\mathrm{W} \& \mathrm{C}$ model, users' satisfaction was influenced by four factors including system quality, service quality, information quality, and communication quality.

D\&M model and W\&C model provide a theoretical model for learning environment evaluation. According to these two theoretical models, the success of online learning environment is determined by five crucial factors: system quality, information quality, service quality, communication quality, and users' satisfaction. Among the five factors, system quality is used to measure the characteristics of learning environment itself, 
including usability, practical applicability, reliability, flexibility, and adaptability. Information quality refers to learning content quality. The learning content provided by e-learning 2.0 environment should have the following characteristics: has the latest tools, permits personalization, sufficient in resources, be intelligible, and is closely related to working or learning. Service quality refers to learning support quality, or whether or not can learners can effectively obtain instruction and help from teachers in time. As proposed by Chen and Hwang (2012), characteristics of Web2.0 are embodied on service rather than on technology. Thus, service quality plays a crucial role in ensuring learners' participation and durability. Communication quality refers to what extent learners can benefit from the dynamic interaction provided by learning environment including sharing, feedback, and discussion. Users' satisfaction, which means learners' attitudes to online learning environment, covers the whole usage experience including software, content, and service. The current research adopted the above five factors as indicators for evaluating the e-learning environment.

\section{Methodology}

\subsection{Population}

The study concentrated on distance learners who studied in the Network Education Institution of Beijing Language \& Culture University and Hong Kong Open University. All of these participants were adults with working experience and took online courses provided by the two universities. Web2.0 technology and tools were adopted by both of the above two universities to help and support students' studies including wiki, blog, BBS, YouTube, RSS, and Facebook. A random sampling technique was adopted to obtain a representative sample. Of the total administered 339 questionnaires, 289 valid ones were retrieved with an effective response rate of $85.2 \%$, including 129 ones from

Table 1. Descriptive statistics of study participants

\begin{tabular}{|c|c|c|c|c|c|}
\hline & & \multicolumn{2}{|c|}{ Beijing Language \& Culture University } & \multicolumn{2}{|c|}{ Hong Kong Open University } \\
\hline & & $\mathbf{N}$ & $\mathbf{p}$ & $\mathbf{N}$ & $\bar{P}$ \\
\hline gender & Male & 56 & $56.6 \%$ & 26 & $83.8 \%$ \\
\hline \multirow[t]{5}{*}{ age } & $<20$ & 5 & $3.9 \%$ & 43 & $26.9 \%$ \\
\hline & $20 \sim 25$ & 38 & $29.5 \%$ & 28 & $17.5 \%$ \\
\hline & $36 \sim 40$ & 12 & $9.3 \%$ & 20 & $12.5 \%$ \\
\hline & $41 \sim 45$ & 9 & $7 \%$ & 12 & $7.5 \%$ \\
\hline & $45 \sim 50$ & 0 & 0 & 2 & $1.3 \%$ \\
\hline \multirow[t]{3}{*}{ Working years } & $<1$ & 0 & 0 & 37 & $23.1 \%$ \\
\hline & $1 \sim 5$ & 50 & $38.8 \%$ & 59 & $36.9 \%$ \\
\hline & $26 \sim 30$ & 1 & $0.8 \%$ & 1 & $0.6 \%$ \\
\hline \multirow{4}{*}{$\begin{array}{c}\text { Years of attending distance } \\
\text { learning }\end{array}$} & $<1$ & 75 & $58.1 \%$ & 52 & $32.5 \%$ \\
\hline & $1 \sim 3$ & 54 & $41.9 \%$ & 60 & $37.5 \%$ \\
\hline & $4 \sim 6$ & 0 & 0 & 46 & $28.8 \%$ \\
\hline & $7 \sim 10$ & 0 & 0 & 2 & $1.3 \%$ \\
\hline TOTAL & & 129 & & 160 & \\
\hline
\end{tabular}


Beijing Language \& Culture University and 160 ones from Hong Kong Open University. Table 1 shows the detail.

\subsection{Instrument}

The current study used the questionnaire survey method to collect information of the five indicators presented in Table 1 and information of students' self-regulated learning. To ensure content validity, items adopted by the questionnaires of the current study were modified from the items of previous related questionnaires. The questionnaires of system quality, information quality, service quality, communication quality, and users' satisfaction were adapted according to the studies of Wang et al. (2007), Sun et al. (2008), Wang et al. (2011) and Liaw et al.(2013). The self-regulated learning questionnaire referred as the Distance scale that included "strongly agree," "agree,"“neutral,"“disagree," and "strongly disagree" in regards to the statement items. The questionnaire included two parts: (1) the first one collected demographic information of subjects such as gender, age, working years, and years of attending distance learning, while (2) the second one collected students' evaluations on system quality, information quality, service quality, communication quality, users' satisfaction, and self-regulated learning.

\subsubsection{Reliability and validity analysis of} questionnaires. Reliability and validity are crucial indicators for measuring effectiveness and reliability of a scale. The following methods were conducted by the current research to ensure the reliability and validity of the questionnaires.

Table 2. Questionnaire structure

\begin{tabular}{|c|c|c|}
\hline Construct & Number of items & Sources \\
\hline System quality & 6 & \multirow{5}{*}{$\begin{array}{c}\text { Wang, Wang \& Shee , } 2007 \\
\text { Sun, Tsai, Finger, Chen, \& Yeh, } 2008 \\
\text { Wang \& Chiu, } 2011 \\
\text { Liaw \& Huang, } 2013\end{array}$} \\
\hline Information quality & 6 & \\
\hline Service quality & 4 & \\
\hline Communication quality & 5 & \\
\hline User satisfaction & 4 & \\
\hline Self-regulation & 7 & Dilireba Zhao \& An, 2010 \\
\hline
\end{tabular}

Learners'Self-regulated Learning Ability Selfrating Scale was developed by the Research Center of Distance Education of Beijing Normal University.

The final questionnaire consisted of 32 items using a 5-point Likert-type
2.2.1.1. Reliability. The internal consistency reliability was conducted to examine the reliability of the questionnaires in the current research.Cronbach acoefficient was calculated for all six dimensions of the questionnaire between the two universities. Table 3 shows that Cronbach'salphafor the six dimensions 
for the two universities all exceeded 0.7, which indicated a high reliability and internal consistency.

2.2.1.2. Content validity. The current study involved a three-phase approach to validate the content of the questionnaires. First, back-translation method was carried out in the process of questionnaire development to ensure construct equivalence in that most of the items were modified from foreign questionnaires. In the process of the questionnaire's development, three bilingual experts who had a good command of English were invited to translate and back-translate items. All of them were experts in the field of distance education with years of overseas study experience. Through the process of the difference in cultures between Hong Kong and the mainland. Therefore, to ensure the consistency of measurement content in the context of different cultures, four Hong Kong natives who researched in the field of distance education were invited to modify the expression of the primarily formed Chinese version questionnaire to finally form the Cantonese version questionnaire.

Third, researchers in the field of distance education and master students that majored in distance education were invited to make conformance judgments for the questionnaire as well as its relevant content. Words that may have caused ambiguity or misunderstanding were modified, and ambiguous or poor relevant items were deleted to ensure all of

Table 3. Cronbach alpha coefficient

\begin{tabular}{|c|c|c|c|}
\hline \multicolumn{4}{|c|}{ Cronbach's $\alpha$} \\
\hline Dimensions & Items in scale & Beijing (N=129) & Hong Kong (N=160) \\
\hline System quality & 6 & 0.864 & 0.830 \\
\hline Information quality & 6 & 0.883 & 0.810 \\
\hline Service quality & 4 & 0.738 & 0.760 \\
\hline Communication quality & 5 & 0.866 & 0.807 \\
\hline User satisfaction & 4 & 0.901 & 0.837 \\
\hline Self-regulation & 7 & 0.852 & 0.885 \\
\hline
\end{tabular}

back-translation, some items which had a different meaning from the original ones were deleted.

Second, many technical terms were expressed in a different way as a result of the items were expressed in an accurate way. The content validity of the questionnaires was guaranteed through all this work.

2.2.1.3. Structure validity. AMOS 2.0 was used to examine structure validity. Goodness 
Table 4. Construct validity

\begin{tabular}{|c|c|c|c|c|}
\hline $\mathbf{x}^{2} / \mathbf{d f}$ & CFI & NFI & RFI & RMSEA \\
\hline 1.01 & 0.998 & 1.000 & 0.990 & 0.008 \\
\hline
\end{tabular}

indices including $\mathrm{x}^{2} / \mathrm{df}$, CFI, NFI, RFI, RMSEA were calculated as Table 4 shows $\mathrm{x}^{2} / \mathrm{df}$ is 1.01 which was less than 3 ; NFI, RFI, CFI is $0.998,0.990,1.000$, all of which were above 0.9 ; RMSEA was 0.008 which had been lower than 0.05 . The results revealed that construct validity was good.

\section{Results}

\subsection{The general comparison between Beijing and Hong Kong}

Independent-samples $\mathrm{T}$ test were used to analyze the differences in six dimensions between the two universities (Table 5).

The results showed that significant difference was found in all six dimensions between distance learners from Beijing and Hong Kong. The system quality, information quality, and service quality of Network Education Institution of Beijing Language \& Culture University were founded to be better than Hong Kong Open University. The communication quality, user satisfaction, as well as self-regulated learning of Beijing Language \& Culture University, were also found to be better than Hong Kong Open University.

Table 5. The general comparison between Beijing and Hong Kong

\begin{tabular}{|c|c|c|c|c|c|}
\hline & school & $\mathbf{N}$ & Mean & $\mathbf{T}$ & sig \\
\hline \multirow{2}{*}{ System quality } & Beijing & 129 & 25.84 & \multirow{2}{*}{13.445} & \multirow{2}{*}{$.000 * * *$} \\
\hline & Hong Kong & 160 & 20.38 & & \\
\hline \multirow{2}{*}{ Information quality } & $\mathrm{BJ}$ & 129 & 24.53 & \multirow{2}{*}{9.317} & \multirow{2}{*}{$.000 * * *$} \\
\hline & $\mathrm{HK}$ & 160 & 20.59 & & \\
\hline \multirow{2}{*}{ Service quality } & BJ & 129 & 16.46 & \multirow{2}{*}{11.715} & \multirow{2}{*}{$.000 * * *$} \\
\hline & HK & 160 & 13.42 & & \\
\hline \multirow{2}{*}{$\begin{array}{c}\text { Communication } \\
\text { quality }\end{array}$} & $\mathrm{BJ}$ & 129 & 20.12 & \multirow{2}{*}{11.010} & \multirow{2}{*}{$.000 * * *$} \\
\hline & $\mathrm{HK}$ & 160 & 16.19 & & \\
\hline \multirow{2}{*}{ User satisfaction } & $\mathrm{BJ}$ & 129 & 16.76 & \multirow{2}{*}{11.531} & \multirow{2}{*}{$.000 * * *$} \\
\hline & HK & 160 & 13.30 & & \\
\hline \multirow{2}{*}{ Self-regulation } & $\mathrm{BJ}$ & 129 & 28.79 & \multirow{2}{*}{13.478} & \multirow{2}{*}{$.000 * * *$} \\
\hline & $\mathrm{HK}$ & 160 & 22.19 & & \\
\hline
\end{tabular}

$* * * \mathrm{p}<.001, * * \mathrm{p}<.01, * \mathrm{p}<.05$ 


\subsection{Demographic Characteristics Difference Analysis}

In this section, difference analysis of demographic characteristics was conducted in the communication dimension, users' satisfaction dimension, and self-regulated learning dimension, all of which represent leaners' experience to online learning environment.

\subsubsection{Gender difference analysis of distance learners'online learning experience.}

First, the general gender differences of online learning experience were analyzed by using a T-test. Table 6 shows the results. learning experience than female students. In addition, male students reported higher selfregulation abilities.

Then gender difference analysis was carried out for the two universities separately to see if the pattern was consistent across different universities. Table 7 shows the results.

For students from Beijing Language \& Culture University, there was only a significant gender difference in the selfregulated learning dimension and men reported higher self-regulated learning ability than women. Students from Hong Kong Open University had significant differences in three

Table 6. The general gender differences

\begin{tabular}{|c|c|c|c|c|c|}
\hline & Gender & $\mathbf{N}$ & Mean & $\mathbf{T}$ & sig. \\
\hline \multirow{2}{*}{$\begin{array}{c}\text { Communication } \\
\text { quality }\end{array}$} & Female & 207 & 17.68 & \multirow{2}{*}{-1.839} & \multirow{2}{*}{.068} \\
\hline & Male & 82 & 18.62 & & \\
\hline \multirow{2}{*}{ User satisfaction } & $\mathrm{F}$ & 207 & 14.58 & \multirow{2}{*}{-2.309} & \multirow{2}{*}{$.022 *$} \\
\hline & M & 82 & 15.50 & & \\
\hline \multirow{2}{*}{ Self-regulation } & $\mathrm{F}$ & 207 & 24.49 & \multirow{2}{*}{-3.342} & \multirow{2}{*}{$.001 * *$} \\
\hline & $\mathrm{M}$ & 82 & 26.76 & & \\
\hline
\end{tabular}

$* * * \mathrm{p}<.001, * * \mathrm{p}<.01, * \mathrm{p}<.05$

The results showed that with the exception of the communication dimension, there was a significant difference between female and male students in users' satisfaction dimension and in self-regulated learning dimension. Male students were more satisfied with their dimensions including communication quality dimension, users' satisfaction dimension, and self-regulated learning dimension. However, women reported higher communication quality, higher satisfaction, and better selfregulation learning ability than men. 
Table 7. The gender difference analysis in Beijing\& Hong Kong

\begin{tabular}{|c|c|c|c|c|c|c|}
\hline School & dimensions & Gender & $\mathbf{N}$ & Mean & $\mathbf{t}$ & sig. \\
\hline \multirow{6}{*}{ Beijing } & \multirow{2}{*}{$\begin{array}{c}\text { Communication } \\
\text { quality }\end{array}$} & $\mathrm{F}$ & 72 & 19.83 & \multirow{2}{*}{-1.098} & \multirow{2}{*}{.274} \\
\hline & & M & 56 & 20.43 & & \\
\hline & \multirow{2}{*}{ User satisfaction } & $\mathrm{F}$ & 72 & 16.46 & \multirow{2}{*}{-1.475} & \multirow{2}{*}{.143} \\
\hline & & M & 56 & 17.09 & & \\
\hline & \multirow{2}{*}{ Self-regulation } & $\mathrm{F}$ & 72 & 28.11 & \multirow{2}{*}{-2.152} & \multirow{2}{*}{$.033 *$} \\
\hline & & $\mathrm{M}$ & 56 & 29.59 & & \\
\hline \multirow{6}{*}{ Hong Kong } & \multirow{2}{*}{$\begin{array}{c}\text { Communication } \\
\text { quality }\end{array}$} & $\mathrm{F}$ & 134 & 16.47 & \multirow{2}{*}{2.764} & \multirow{2}{*}{$.006^{* *}$} \\
\hline & & $\mathrm{M}$ & 26 & 14.73 & & \\
\hline & \multirow{2}{*}{ User satisfaction } & $\mathrm{F}$ & 134 & 13.54 & \multirow{2}{*}{2.645} & \multirow{2}{*}{$.009 * *$} \\
\hline & & M & 26 & 12.08 & & \\
\hline & \multirow{2}{*}{ Self-regulation } & $\mathrm{F}$ & 134 & 22.49 & \multirow{2}{*}{1.999} & \multirow{2}{*}{$.047 *$} \\
\hline & & M & 26 & 20.65 & & \\
\hline
\end{tabular}

$* * * \mathrm{p}<.001, * * \mathrm{p}<.01, * \mathrm{p}<.05$

\subsubsection{Age difference analysis of distance learners'online learning experience.}

ANOVA was conducted to analyze age difference of the whole subjects' online learning experiences. Table 8 shows the results.

An analysis of variance (ANOVA) on user's satisfaction revealed significant variation among students from different age groups. However, Post Hoc analysis indicated that there was no significant difference between any different age groups.

An ANOVA was carried out separately in Beijing Language \& Culture University and in Hong Kong Open University to analyze students' online learning experiences of different age groups in the current study.

Table 8 . The general age differences

\begin{tabular}{|c|c|c|c|c|c|c|}
\hline & & SS & df & MS & F & Sig. \\
\hline $\begin{array}{c}\text { Communication } \\
\text { quality }\end{array}$ & $\begin{array}{c}\text { Between } \\
\text { groups }\end{array}$ & 135.176 & 6 & 22.529 & 1.769 & .105 \\
\hline User satisfaction & $\begin{array}{c}\text { Between } \\
\text { groups }\end{array}$ & 141.883 & 6 & 23.647 & 2.607 & $.018^{*}$ \\
\hline Self-regulation & $\begin{array}{c}\text { Between } \\
\text { groups }\end{array}$ & 329.147 & 6 & 54.858 & 2.008 & .065 \\
\hline
\end{tabular}

$* * * \mathrm{p}<.001, * * \mathrm{p}<.01, * \mathrm{p}<.05$ 
The results showed that students from different age groups did not differ significantly in any of the three dimensions for students from Beijing Language \& Culture University and from Hong Kong Open University.

\subsubsection{Working years difference analysis of distance learners' online learning experience.}

An ANOVA was conducted to analyze difference in the working years of all subjects' online learning experiences (see Table 9). were 6-10 years or 11-15 years reported better users' satisfaction and better self-regulated learning abilities as compared to those whose working years were less than 1 year.

Working years difference analysis were carried out separately in Beijing Language \& Culture University and Hong Kong Open University(see Table 11). The results showed that working years had non-significant difference in all of the three dimensions for Hong Kong Open University. While for Beijing Language \& Culture University,

Table 9. The general differences in working years

\begin{tabular}{|c|c|c|c|c|c|c|}
\hline & & $\begin{array}{c}\text { Sum of } \\
\text { Square }\end{array}$ & df & $\begin{array}{c}\text { Mean } \\
\text { Square }\end{array}$ & F & Sig. \\
\hline $\begin{array}{c}\text { Communication } \\
\text { quality }\end{array}$ & $\begin{array}{c}\text { Between } \\
\text { groups }\end{array}$ & 223.652 & 6 & 37.275 & 3.000 & $.007^{* *}$ \\
\hline User satisfaction & $\begin{array}{c}\text { Between } \\
\text { groups }\end{array}$ & 186.565 & 6 & 31.094 & 3.489 & $.002^{* *}$ \\
\hline Self-regulation & $\begin{array}{c}\text { Between } \\
\text { groups }\end{array}$ & 520.142 & 6 & 86.690 & 3.254 & $.004^{* *}$ \\
\hline
\end{tabular}

$* * * \mathrm{p}<.001, * * \mathrm{p}<.01, * \mathrm{p}<.05$

An analysis of variance (ANOVA) on all of the three dimensions yielded significant variation among students who have different working years. Post-hoc test was carried out in the current research to further analyze the difference (see Table 10).

The results showed that learners whose working years were less than 1 year differed significantly from those whose working years were 1-5 years or 11-15 years in communication quality dimension. Learners whose working years were 1-5 years or 11-15 years reported higher communication quality than those whose working years were less than 1 year.

In addition, learners whose working years working years had significant difference in the communication dimension and self-regulated dimension.

Pairwise comparison was used as a posthoc test to determine the differences. The results showed that working years only had significant difference in the self-regulated learning dimension.

Post-hoc test results showed that for students from Beijing Language \& Culture University, working years in self-regulated learning dimension mainly existed between learners whose working years were 6-10 $(\mathrm{MD}=-3.519, \mathrm{p}<0.05)$ and learners whose working years were $11-15$ years $(\mathrm{MD}=3.519$, $\mathrm{p}<0.05$ ).Learners whose working years were 
How Can Self-regulated Learning Be Supported in E-learning 2.0 Environmsent: a Comparative Study

Table 10. The post-hoc test for differences in working years

\begin{tabular}{|c|c|c|c|c|}
\hline & $\begin{array}{c}\text { (I)working } \\
\text { years }\end{array}$ & $\begin{array}{l}(\mathrm{J}) \text { working } \\
\text { years }\end{array}$ & $\begin{array}{c}\text { Mean } \\
\text { Difference (I-J) }\end{array}$ & Sig. \\
\hline \multirow{6}{*}{$\begin{array}{c}\text { Communication } \\
\text { quality }\end{array}$} & \multirow{6}{*}{1} & 2 & -2.462 & $.039 *$ \\
\hline & & 3 & -2.528 & .063 \\
\hline & & 4 & -2.947 & $.040^{*}$ \\
\hline & & 5 & -2.470 & .244 \\
\hline & & 6 & -2.583 & .788 \\
\hline & & 7 & -3.797 & .899 \\
\hline \multirow{6}{*}{ User satisfaction } & \multirow{6}{*}{1} & 2 & -1.915 & .082 \\
\hline & & 3 & -2.447 & $.017 *$ \\
\hline & & 4 & -2.608 & $.025 *$ \\
\hline & & 5 & -2.281 & .152 \\
\hline & & 6 & -2.680 & .578 \\
\hline & & 7 & -3.608 & .836 \\
\hline \multirow{6}{*}{ Self-regulation } & \multirow{6}{*}{1} & 2 & -3.126 & .124 \\
\hline & & 3 & -4.093 & $.024 *$ \\
\hline & & 4 & -4.408 & $.032 *$ \\
\hline & & 5 & -4.074 & .124 \\
\hline & & 6 & -3.680 & .809 \\
\hline & & 7 & -5.108 & .932 \\
\hline
\end{tabular}

$* * * \mathrm{p}<.001, * * \mathrm{p}<.01, * \mathrm{p}<.05$

Table 11. Working years differences in different school

\begin{tabular}{|c|c|c|c|c|c|c|c|}
\hline \multirow{2}{*}{ School } & \multicolumn{2}{|c|}{ dimensions } & SS & df & MS & F & Sig. \\
\hline \multirow{4}{*}{ Beijing } & $\begin{array}{c}\text { communication } \\
\text { quality }\end{array}$ & $\begin{array}{c}\text { Between } \\
\text { groups }\end{array}$ & 110.319 & 4 & 27.580 & 3.181 & $.016^{*}$ \\
\cline { 2 - 8 } & User satisfaction & $\begin{array}{c}\text { Between } \\
\text { groups }\end{array}$ & 53.801 & 4 & 13.450 & 2.415 & .052 \\
\cline { 2 - 9 } & Self-regulation & $\begin{array}{c}\text { Between } \\
\text { groups }\end{array}$ & 209.135 & 4 & 52.284 & 3.712 & $.007 * *$ \\
\hline
\end{tabular}

$* * * \mathrm{p}<.001, * * \mathrm{p}<.01, * \mathrm{p}<.05$ 
between 11-15 years were found to be better than learners whose working years were between 6-10 years.

\subsubsection{Years of attending distance learning difference analysis of distance learners' online learning experience.}

First, an ANOVA was conducted in the current study to analyze years of attending distance learning difference of the whole subjects' online learning experiences(see Table 12).
Significant difference was only found in the self-regulated dimension (see Table 13).

The results of post-hoc test showed that Learners who attended distance learning for 4-6 years had significant difference with those who attended distance learning for less than 1year or between 1-3 years in the selfregulated learning dimension. Learners who attended distance learning for less than 1 year and between 1-3 years were found to be better than those who attended distance learning for 4-6 years in the self-regulated dimension.

Table 12. The general differences of years of attending distance learning

\begin{tabular}{|c|c|c|c|c|c|l|}
\hline \multicolumn{2}{|c|}{} & SS & df & MS & F & \multicolumn{1}{c|}{ Sig. } \\
\hline communication quality & $\begin{array}{c}\text { Between } \\
\text { groups }\end{array}$ & 114.240 & 3 & 38.080 & 3.004 & $.031^{*}$ \\
\hline User satisfaction & $\begin{array}{c}\text { Between } \\
\text { groups }\end{array}$ & 62.691 & 3 & 20.897 & 2.258 & .082 \\
\hline Self-regulation & $\begin{array}{c}\text { Between } \\
\text { groups }\end{array}$ & 289.253 & 3 & 96.418 & 3.548 & $.015^{*}$ \\
\hline
\end{tabular}

$* * * \mathrm{p}<.001, * * \mathrm{p}<.01,{ }^{*} \mathrm{p}<.05$

The results showed that years of attending distance learning difference had significant difference in communication dimension and in self-regulated learning dimension. Further analysis of post-hoc test was conducted.
An ANOVA was separately conducted to analyze years of attending distance learning difference between Beijing Language \& Culture University and Hong Kong Open University.

Table 13. The post hoc test for general differences of years of attending distance learning

\begin{tabular}{|c|c|c|c|c|}
\hline & $\begin{array}{c}\text { (I)working } \\
\text { years }\end{array}$ & $\begin{array}{c}\text { (J) working } \\
\text { years }\end{array}$ & $\begin{array}{c}\text { Mean } \\
\text { Difference (I-J) }\end{array}$ & Sig. \\
\hline \multirow{3}{*}{ Self-regulation } & \multirow{2}{*}{3} & 1 & -2.739 & $.027^{*}$ \\
\cline { 3 - 5 } & & 2 & -2.635 & $.041^{*}$ \\
\cline { 2 - 5 } & & 4 & -.109 & 1.000 \\
\hline
\end{tabular}

$* * * \mathrm{p}<.001, * * \mathrm{p}<.01,{ }^{*} \mathrm{p}<.05$ 
The results showed that years of attending distance learning had a non-significant difference in three dimensions for distance learners from Beijing Language \& Culture University. For distance learners from Hong Kong Open University, years of attending distance learning had significant difference in users' satisfaction dimension $(\mathrm{F}=4.106$, $\mathrm{p}<0.01)$. A post-hoc test was conducted to further analyze the difference. Table 14 shows the results.

The results of post-hoc test showed that for distance learners from Hong Kong Open
University, years of attending distance learning mainly had significant difference between learners who attended distance learning for less than 1 year and those who attended distance learning for 1-3 years, and between learners who attended distance learning for less than 1 year and those who attended distance learning for 4-6 years. Learners who attended distance learning for 1-3 years or 4-6 years were found to be better than those who attended distance learning for less than 1 year in users' satisfaction dimension.

Table 14. The post hoc test for years of attending distance learning in Hong Kong Open University

\begin{tabular}{|c|c|c|c|c|}
\hline & $\begin{array}{l}\text { (I) years of } \\
\text { learning }\end{array}$ & $\begin{array}{l}\text { (J) years of } \\
\text { learning }\end{array}$ & MD (I-J) & Sig. \\
\hline \multirow{12}{*}{ User satisfaction } & \multirow{3}{*}{1} & 2 & -1.412 & $.040 *$ \\
\hline & & 3 & -1.625 & $.022 *$ \\
\hline & & 4 & -1.212 & .933 \\
\hline & \multirow{3}{*}{2} & 1 & 1.412 & $.040 *$ \\
\hline & & 3 & -.213 & .980 \\
\hline & & 4 & .200 & 1.000 \\
\hline & \multirow{3}{*}{3} & 1 & 1.625 & $.022 *$ \\
\hline & & 2 & .213 & .980 \\
\hline & & 4 & .413 & .997 \\
\hline & \multirow{3}{*}{4} & 1 & 1.212 & .933 \\
\hline & & 2 & -.200 & 1.000 \\
\hline & & 3 & -.413 & .997 \\
\hline
\end{tabular}

$* * * \mathrm{p}<.001, * * \mathrm{p}<.01, * \mathrm{p}<.05$ 


\subsection{Differences Analysis for Relationship between Self-regulation and Environment}

The author had developed a model to explain the relationship between selfregulation and e-learning 2.0 environment as Fig. 1 shows (Hong, 2014, unpublished result). In this model, system quality, information quality, service quality, and user satisfaction were tested to be key factors affecting self-regulation in the e-learning 2.0 environment. User satisfaction was proved to be the most significant intermediary variable. Communication quality impacts self-regulation through user satisfaction. The
Fig 3shows the final model for Hong Kong Open University.

For Beijing Language \& Culture University, self-regulation was predicted by information quality, communication quality, and user satisfaction. For Hong Kong Open University, self-regulation was affected by system quality, information quality, communication quality, and user satisfaction. System quality is the only statistical difference for both universities. In both universities, the path analysis demonstrates that communication quality and user satisfaction were the most significant intermediary variable. Statistic

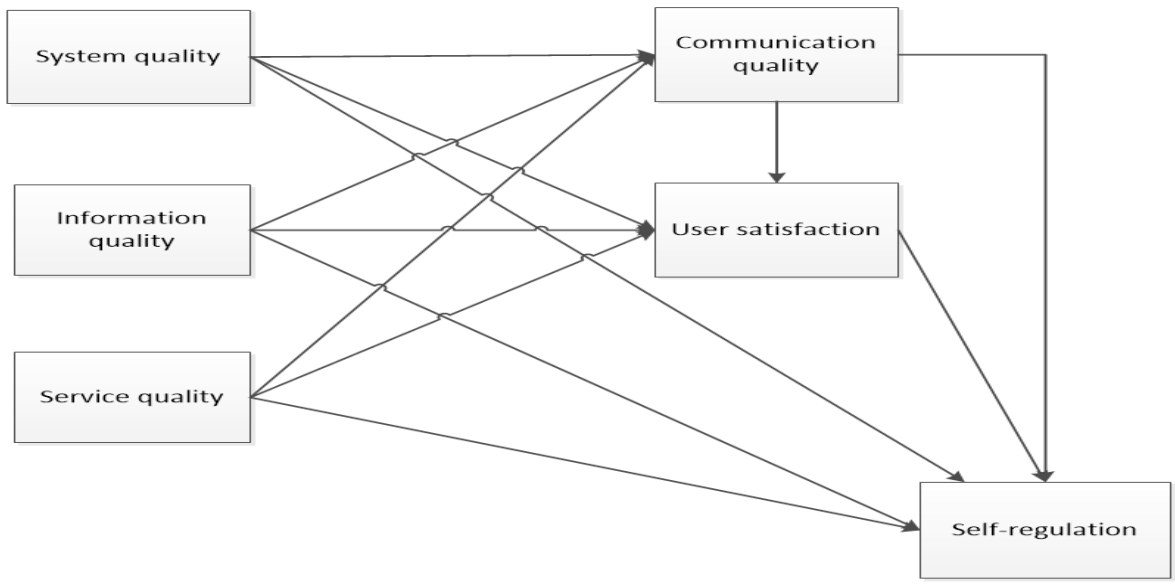

Figure 1. Hong's research model (2014)

directions of arrows show the positive impact of environmental variables on self-regulation.

In this article, the model was tested again separate regression analysis in different schools. The author tried to find whether there were differences in the relationship between self-regulation and environment in different areas and school. Fig 2 shows the final model for Beijing Language \& Culture University; result also presented evidence that user satisfaction played an important role for selfregulation in both schools. It corresponded to the author's earlier study results. The connection from communication quality to self-regulation is significant for both universities, which was different from the early results. 


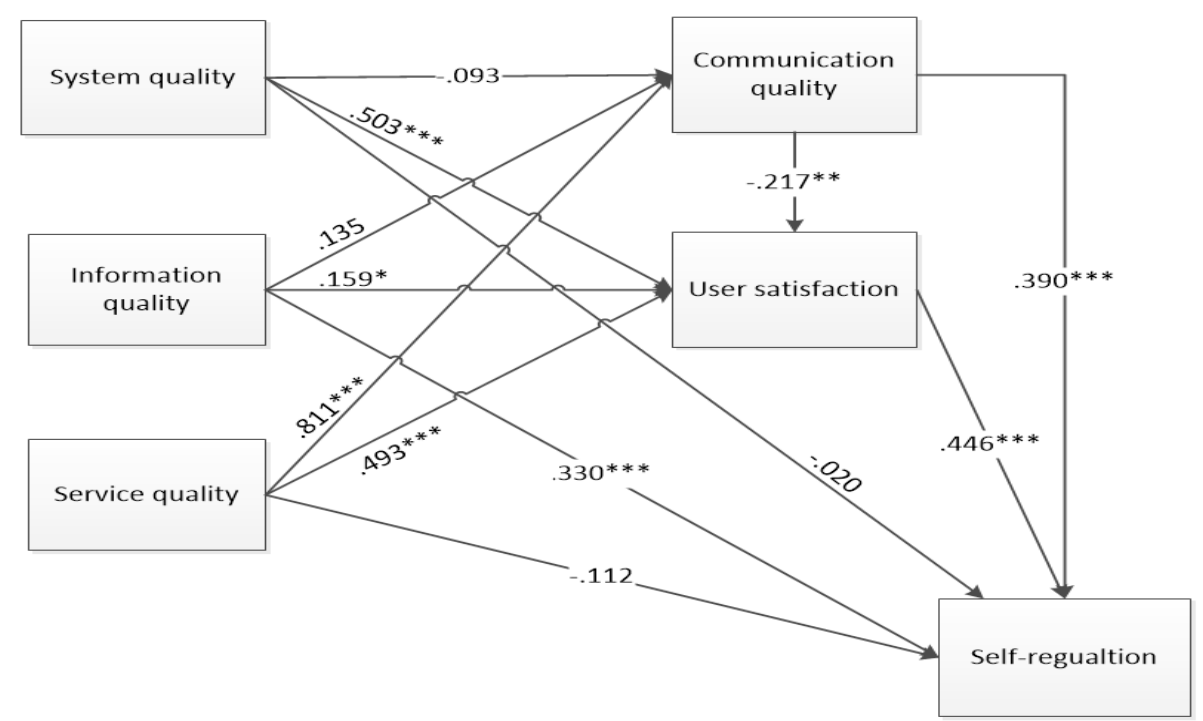

Figure 2. Model for Beijing Language \& Culture University

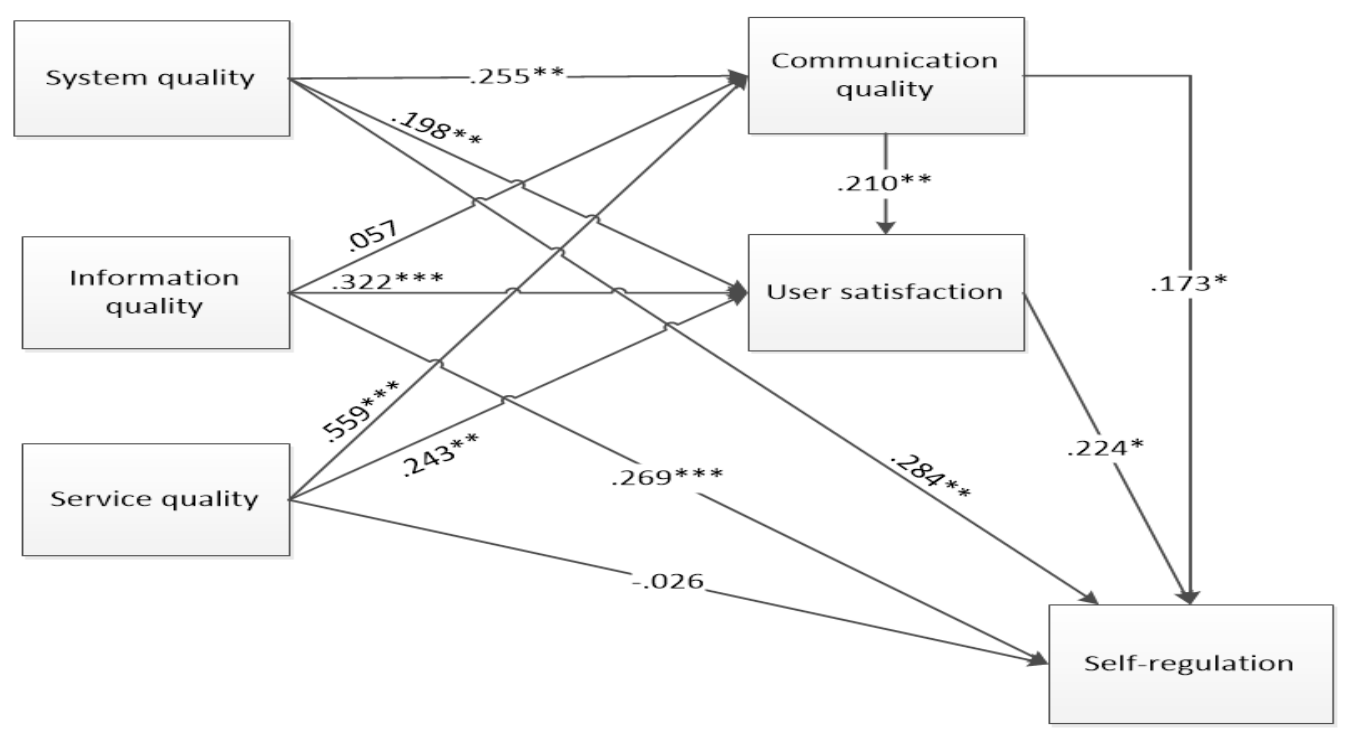

Figure 3. Model for Hong Kong Open University 


\section{Discussion}

In this study, the online learning environment in Beijing Language \& Culture University were found to be better than Hong Kong Open University. The learning experience of distance learners from Beijing Language \& Culture University were also found better than the learners from Hong Kong Open University. The results corresponded with the teaching situation of the above two universities. At Hong Kong Open University, the online learning and faceto-face tutoring were offered blended. Faceto-face interactions were arranged at a fixed time every week while the online learning environment was mainly designed for learners to acquire course's information, discuss issues online, submit assignments, and so on. The interactions between teachers and students mainly occurred during the process of faceto-face tutoring. However, Beijing Language \& Culture University offered students with a fully online program whereby registration, curricula-variable, course learning, questions and answering, and assignment submissions happened on the learning platform. Learning support provided by teachers was also achieved based on the network platform. Therefore, students from Beijing Language \& Culture University reported better on the online learning environment and enhanced learning experiences than students from Hong Kong Open University.

Furthermore, the analysis of demographic characteristics suggests that for whole subjects, users'satisfaction and selfregulation ability of men were found to be better than that of women. However, the results of difference analysis carried out separately in the two universities suggest that there was only a significant difference between female students and male students in the self-regulated learning dimension for students from Beijing Language \& Culture University. Men were found to be better than women. The results were consistent with previous research studies Hongetal., 2014). As proposed by Hong, mainland China was a male-dominated society and this particular culture had a unique understanding about the different social divides of labor and duties for men and women. Men had more opportunities to control their lives compared to women. Women were more dependent upon men. This traditional Chinese perception of gender leads to gendered stereotypes. Besides, it may also contribute to the difference of self-regulated learning between men and women. However, the analysis of gender difference presented completely opposite results for distance learners from Hong Kong Open University. The significant differences were found in the three dimensions. Women were found to be better than men. Subjects' backgrounds may play a role in the results. Subjects from Hong Kong Open University mainly majored in nursing where most of the subjects were women, thus women may have an advantage in the learning process.

Different results were also presented in the current study through age difference analysis based upon examining different regions and universities. Results suggested that gender difference had an impact on online learning. However, students from different regions, different universities, different majors, and different gender presented difference in online learning process.

No matter for the whole subjects or for individual university, age difference had no significant difference in any of the three dimensions. The results were in line with previous research that found age difference to have had no impact on learners' online learning experience (Cui et al., 2014; Richardson \& Swan, 2003). 
For the whole subjects, working years had a significant difference in the three dimensions. The difference mainly existed between learners whose working years were less than 1 year and learners whose working years were between 1-5 years and for learners whose working years were between 6-10 years and learners whose working years were from 11-15 years. Learners whose working years were 1-5 years or 11-15 years reported better communication quality than those whose working years were less than 1 year did. Learners whose working years were between 6-10 years or 11-15 years reported better satisfaction and better self-regulated learning ability than those whose working years were less than 1 year. For students from Hong Kong Open University, differences in any of the three dimensions among different working year groups were not significant. For students from Beijing Language \& Culture University, the comparison between the 6-10 working years group and 11-15 working year groups showed a significant difference. Students who had longer working years reported better self-regulated learning abilities. Therefore, students' working experiences may have had an impact on their online learning experience, especially on the self-regulated learning process. Students with longer working years and more working experience had better online learning outcomes. Liuand Ginther (1999) pointed out that compared to younger students, older students tended to have more motivation to learn and set more clear learning objectives, thus have had better online learning outcomes.

For whole subjects, significant differences in self-regulated learning ability were found among students who have different years of attending distance learning. Learners who attended distance learning for less than 1 year were reported higher self-regulated learning ability as compared to students who attended distance learning for 4-6 years.
Researchers found that time management and self-regulated learning were two major problems encountered by students except tuition (Zhang, 2003).Examples and help were provided for students as far as possible by Beijing Language \& Culture University and Hong Kong Open University in the process of designing and developing online learning environments to help students overcome these problems. Both of the universities provided a lot of personalized support and tutorship for first-year students in the aspect of learning guidance that covered registration, curriculavariable, learning method and learning process, which did help first-year students' self-regulated learning.

The results of difference analysis separately carried out between the two universities showed no significant difference in any of the three dimensions among students who have different years of attending distance learning for Beijing Language \& Culture University. While students from Hong Kong Open University had a significant difference in user satisfaction. Learners who attended distance learning for 1-3 years or 4-6 years reported higher satisfaction than those who attended distance learning for less than 1 year. These results suggest that students' online learning experiences may have impacted their online environment satisfaction. These results were consistent with previous research studies. Atkinson and Kydd (1997) found that online learning experience was a good indicator for evaluating students' attitudes to online learning. Dziuban and Moskal (2001) also found that students with richer online learning experiences tended to be more satisfied with online learning. This also had been proved in the experimental studies conducted by other researchers. For example, Wu et.al. (2014) found that there was a significant difference in learning satisfaction between learners who had online learning experience (such as MOOCs) 
and those who never had online learning experience.

In this study, the relationship between e-learning 2.0 environment and self-regulation were tested in different areas and between the two universities. The results indicate that factors of e-learning environment influencing self-regulation were similar in both universities. Self-regulation was significantly influenced by information quality, communication quality, and user satisfaction in both universities. System quality and service quality also influenced self-regulation by way of communication quality and user satisfaction as the intermediated variable in both universities. The results supported previous research ideas that self-regulated learning process was guided and organized by successful learning environment (Kitayama, 2002; Vighnarajak et al., 2009). Communication quality significantly predicted both user satisfaction and self-regulation, which was consistent with previous research results that high quality of interaction and communication can improve user satisfaction and promote self-regulation (Chen, 2009; Wang \& Chiu, 2011).Liaw and Huang (2013) also stated that a satisfactory environment should be an effective interactive environment which was conducive to self-regulation. This study provided evidence that user satisfaction was one of the most important factors in assessing the success of e-learning environment. The data yielded by this study provided strong evidence that user satisfaction was a key intermediated factor for selfregulation in e-learning environment in both universities. System quality, information quality, and service quality all significantly predicted user satisfaction and furthered self-regulation. Current research appears to validate such a result. For example, Liaw and Huang (2013) had put forward the view that enhancing user satisfaction can promote learners' self-regulation in an e-learning environment.

\section{Conclusion}

The results of this research have significant implications on the construction of online learning environments to promote online learning experiences for distance learners, especially self-regulation. The factors affecting self-regulation in e-learning environments were identified and further proved to be similar in different cultures and areas. There was compelling evidence confirming the opinion that user satisfaction played a key role for e-learning success and self-regulation. This research turned out to validate this conclusion. User satisfaction covers the entire usage experience including technology, content and service, which represent learner's attitude toward e-learning environment (DeLone \& McLean, 2003).Many variables have been proved to have strong correlation with satisfaction in e-learning environment. Results recommend that future research explore other variables affecting user satisfaction and examine their effects on selfregulated learning. 


\section{References}

AI-Harthi, A. S. (2010). Learner selfregulation in distance education: A crossculture study.

The American Journal of Distance Education, 24, 135-150.

Arbaugh, J. B. (2000). Virtual classroom characteristics and student

Satisfaction with Internet-based MBA courses. Journal of Management Education, 24(1), 32-54.

Atkinson,M.,\&Kydd,C.(1997).Individual characteristics associated with World Wide Web use: An empirical study of playfulness and motivation. The Data Base for Advances in Information Systems, 28(2), 53-62.

Azevedo, R., Cromley, J.G., \& Seibert, D. (2004). Does adaptive scaffolding facilitate students' ability to regulate their learning with hypermedia? Contemporary Educational Psychology, 29, 344-370.

Chen, S.C., Yen, D.C.,\& Hwang, M.I. (2012). Factors influencing the continuance intention to the usage of Web 2.0: An empirical study. Computers in Human Behavior,28, 933-941.

Chen, C.M. (2009). Personalized E-learning system with self-regulated learning assisted mechanisms for promoting learning performance. Expert System with Applications, 36, 8816-8829.

Dziuban, C., Moskal, P.(2001). Evaluating distributed learning at metropolitan universities. Educause Quarterly,24 (4), 60-61.

DeLon, W.H.,\& McLean, E.R.(2003). The DeLon and McLean model of information systems success: a ten-year update. Journal of Management Information System, 19(4), 9-30.

González-Gómez, F., Guardiola, J., Rodriguez, Ó. M., Alonso, M. Á. M.(2012). Gender differences in e-learning satisfaction. Computers Education, 58(1), 283-290.

Cui, G.Q., Han, X.B., \&Wang, S.Y.(2014). Effects of students' locus of control and other characteristics on their satisfaction with online learning. China Educational Technology, 8, 55-61.

Harrison, D. (2011). Can blogging make a difference? Available from http://campustechnology.com/ articles/2011/01/12/can-blogging-make-adifference.aspx 2011.1.12

Hilton, J. 2009). Essential versus strategic IT investments. EDUCAUSE Review, July/ August, 8-9.

Hong, Z., Chen, L., \&Panda, S. (2014).Selfregulated learning ability of Chinese distance learners. British Journal of Educational Technology, 45(5), 941-958.

Kramarski, B, \& Gutman, M. (2006). How can self-regulated learning be supported in mathematical e-learning environments? Journal of Computer Assisted Learning, 22, 24-33.

Kitayama, S.(2002).Culture and basic psychological processes-Toward a system view of culture: Comment on Oyserman et al. (2002). Psychological Bulletin, 128(1), 89-96.

Kitsantas, A., \&Dabbagh, N. (2010). Learning to learn with integrative learning technologies (ILT): a practical guide for academic success. Greenwich, Connecticut: Information Age.

Liaw, S. S., \& Huang, H.M. (2007). Developing a collaborative e-learning system based on users' perceptions. Lecture Notes in Computer Science, 4402, 751-759.

Liaw, S. S., \& Huang, H.M. (2013). Perceived satisfaction, perceived usefulness and interactive learning environments as predictors to self-regulation in e-learning environments. Computer \& Education, 60, 14-24. 
Liu, Y., \& Ginther, D. (1999). Cognitive styles and distance education. Online Journal of Distance Learning Administration,2(3). http://www.westga.edu/ distance/ojdla/ fall23/liu23.html

English, M. C., \& Kitsantas, A.(2013). Supporting student selfregulated learning in problem-and projectbased learning. Interdisciplinary Journal of Problem-based Learning, 7(2), 128150.

Markauskaite, L.(2006). Gender issues in preservice teachers' training: ICT literacy and online learning. Australasian Journal of Educational Technology, 22(1), 1-20.

Ong, C. H., \&Lai, J. Y. (2006). Gender differences in perceptions and relationships among dominants of e-learning acceptance. Computers in Human Behavior,22 (5), 816-829.

Roca, J.C.,\& Gagne, M.(2008). Understanding e-learning continuance intention in the workplace: a self-determination theory perspective. Computers in Human Behavior,24, 1585-1604.

Richardson, J. C., \&Swan, K. (2003). Examining social presence in online courses in relation to students' perceived learning and satisfaction. Journal of Asynchronous Learning Networks, 7 (1), 68-88.

Seddon, P. B.(1997). A respecification and extension of the DeLone and McLean model of IS success. Information System Research, 8(3), 240-253.

Shee, D.,\& Wang, Y.H.(2008). Multi-criteria evaluation of the web-based e-learning system: a methodology based on learner satisfaction and its applications. Computers \& Education, 50, 894-905.

Sun, P. C., Tsai, R. J., Finger, G, Chen, Y. Y., \& Yeh, D. (2008). What drives a successful e-learning? An empirical investigation of the critical factors influencing learner satisfaction. Computer \& Education, 50,
1183-1202.

Wang, H.C., \& Chiu, Y. F. (2011). Assessing e-learning 2.0 system success. Computer \& Education, 57, 1790-1800.

Wang, Y.S., Wang, H.Y., \& Shee, D.Y. (2007). Measuring e-learning systems success in an organizational context: Scale development and validation. Computers in Human Behavior, 23, 1792-1808.

Wu, X.M, Yong, W.J., Dai, L. Jia, J.Y., Wang, A.H., W., \&Miao, J. M. (2014). The study of the students' learning experience of the online course based on the course pedagogical model. China Educational Technology, 6, 11-17.

Zhang, W.Y. (2003). A survey of online teaching in Asia's Open Universities. Distance Education in China, 9, 35-42.

Zimmerman, B.J.,\& Schunk, D.H. (2001). Self-regulated learning and academic achievement: theoretical perspectives. Mahwah, New Jersey: Lawrence Erlbaum.

\section{Contact the Author}

\section{Hong Zhao}

lecturer,

Beijing Normal University

Email: u zhaohong@bnu.edu.cn

\section{Li Chen}

Professor, Beijing Normal University

Email: 1chen@bnu.edu.cn 